\title{
Change Management Strategies for Effective Enterprise Resource Planning Systems: A Case Study of a Saudi Company
}

\author{
Hailah Alballaa, Abdullah S. Al-Mudimigh \\ Department of Information Systems \\ College of computer \& Information sciences \\ King Saud University, Riyadh
}

\begin{abstract}
ERP systems offer enormous benefits to organizations in efficiency, productivity, quality management, cost reduction and decision making-speed. Implementing ERP usually involves applying change management strategies. In this paper different change management strategies for ERP implementation in the literature has been reviewed and a case study of National Prawn Saudi based Company has been presented.
\end{abstract}

\section{Keywords}

ERP, Change Management, Implementation, National Prawn Company.

\section{INTRODUCTION}

The enterprise resource planning (ERP) system is integrated information system software compromised of several modules that share a central database. It helps automate and integrate business processes and practices within a firm, and provides support for core organizational activities such as manufacturing, finance and accounting, sales and marketing, and human resources. Moreover, ERP provides access to information in a real time environment (Aladwani 2001; Almudimigh 2001; Kerimoglu 2006; Jing 2007; Trieu 2010).

Implementing ERP is an extensive challenge. The performance of the firm is expected to get worse before it gets better and firms are expected to encounter the resistance throughout the states of ERP implementations (Ross 1999).

Several researchers have developed different models for ERP implementation; and in spite of their differences, all of them extend from the beginning of the project to going live.

(Jing 2007) argues that the implementation of ERP systems is time-consuming, expensive and arduous task. It states that $44 \%$ of the surveyed companies in that study reported that they had spent at least four times as much on implementation as they had on software licenses.

There are many difficulties associated with implementing ERP and in spite of their benefits many ERP systems fail (Aladwani 2001; Chen 2009). The high failure rate of ERP implementation calls for a better understanding of its critical success factors(Nah 2003).

(Nah 2003) identified the following11 critical success factors for ERP found in the literature: Appropriate Business and IT legacy Systems, Business plan and vision, Business Process Reengineering (BPR), Change Management Culture and Program, Effective communication, ERP teamwork and composition, Monitoring and evaluation of Performance, Project Champion, Project management, Software
Development, Testing and Troubleshooting, Top Management Support.

It is important to know that most of these factors are interrelated and impinge on one another. In this paper we concentrate on change management.(Ngai 2008)

(Almudimigh 2001) suggested that among ERP critical success factors the five key critical success factors are top management support, business case, change management, project management and training. Among the key critical success factors change management was found to be one of the most important critical success factors in ERP implementation (Hawking 2004; Trieu 2010).

In this paper we will focus on change management and change management strategies.

\section{CHANGE MANAGEMENT}

It is estimated that approximately one-half of all ERP projects fail to achieve anticipated benefits due to underestimating the efforts involved in managing change (Appleton 1997).

Change management is required to prepare users for the introduction of the new systems, reduce resistance towards the system and influence user attitudes towards change (Kemp 2008).

(Foster 2007) showed that $90 \%$ of companies that applied change management to ERP implementations believed that it had a strong impact on the success of the project.

Change management is a set of tools, activities, processes, and principles that support employee understanding and organizational shifts from a current state to desired future state during the implementation of ERP systems to achieve the organizational outcome. (Almudimigh 2001).

\section{CHANGE STRATEGIES}

MANAGEMENT

Change management is primary concerned with people challenges during ERP implementation. Several studies suggested that people Challenges (soft issues) are more difficult to manage than the technical problems (Aladwani 2001).

It is argued that successful change management is brought about through the implementation of change management strategies (Ngai 2008).

Change management is important, starting at the project phase and continuing throughout the entire life cycle (Nah 2001).

Different authors have different views of the scope of the change management mandate, but they all include activities 
and introduce ideas that help end-users to learn and effectively use the ERP. Typically, these activities start from setting of the project's vision and end with any postimplementation activities (Calvert 2006).

One of main people challenges when it comes to change management is people resistance to change (Jing 2007). The sources and types of resistance to change may vary. In order to reduce employees' resistance to ERP implementation, top management of the organization must analyze the sources of resistance and employ the appropriate set of strategies to offset them.(Aladwani 2001). Moreover, it is critical for all change management managers to understand the values of their organizations and culture because they influence the way change will be accepted and adopted.

Overcoming user resistance involves determining who resisting change, individuals or groups. A lot of times people are ready to change their technological platform but not the organizational processes (Ross 1999).

Many researchers looked into the reason for user resistance. Possible reasons for user resistance include: loss of power and status, unclear strategic vision, extensive project schedules and more working hours, Modest financial return or no value added to the company's performance, high cost exceeding the budgeted amount... etc

(Kotter 1979; Joshi 1991; Shang 2004) consolidated the reasons people resist change into four major categories: parochial self-interest, misunderstanding and lack of trust, different assessment, low tolerance for change and increased effort.

Resistance behaviors vary in type and intensity; (Shang 2004) organize resistance behaviors into three types: nondestructive, proactively-destructive, and passively-destructive.

Different Researchers propose different models for change management and overcoming user resistance. For example, (Zafar 2006) proposed a model for change management, managing user resistance and successful ERP implementation; It suggested organizational resistance is expected to be negatively related to implementation success, achievement of predetermined goals and user satisfaction. See Figure 1: Change Management Model From (Zafar 2006).

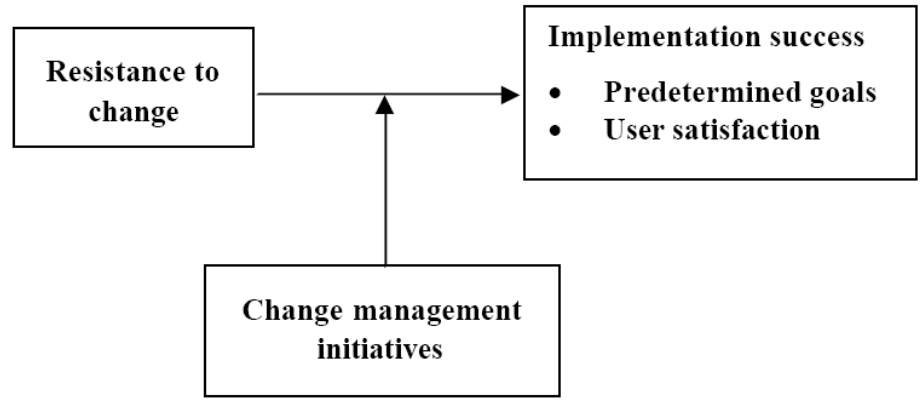

Figure 1: Change Management Model

The change management initiatives such as getting the employees involved, attending to employees concerns, and making available support groups will mitigate the effect of resistance to change and enhance implementation success. The negative relationship between resistance to change and achievement of predetermined goals and user satisfaction will be lower when change management initiatives are higher.

(Aladwani 2001) suggests approaches for change management from marketing research. In addition, he suggests a processoriented framework consisting of three phases: knowledge formulation, strategy implementation, and status evaluation. It assumes that change management and management support should positively influence system awareness, feelings towards the system and the intention to adopt that system for users to actually adopt the system.

(Kerimoglu 2006) proposes a model for optimizing change management and implementing ERP successfully; it suggests the gaps between technology, human and organization should be minimized. The point surrounded by a dashed circle is the optimal point where the gaps are minimized. There are 3 places where compatibility is of concern:

- Between technology and organization

- Between technology and human

- Between human and organization

By reaching the optimal point utilization of ERP systems will be maximized. See Figure 2: Actors of ERP project. It suggests an effective and appropriate change management plan should be applied for each stage where incompatibilities take place.

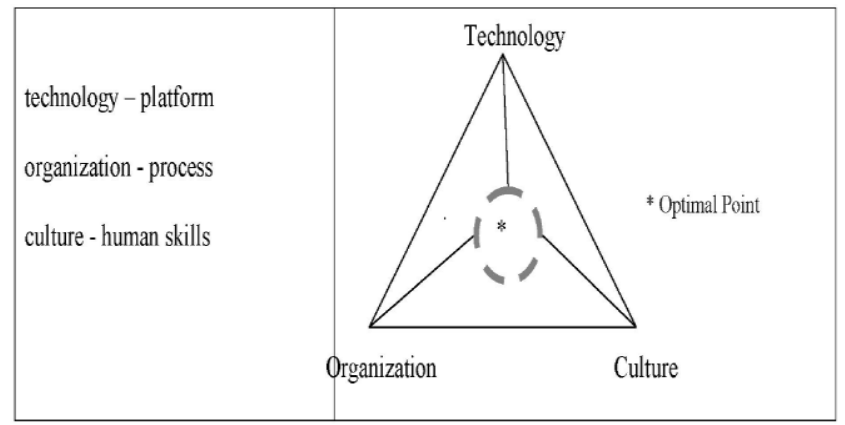

Figure 2: Actors of ERP project

(Trieu 2010) identified the following 9 change management strategies for successful ERP:

1. Top management support: top management support needs to be included in each step and in all company levels.

2. Project Teams: team work was found to be important and project teams supporting the change management process are crucial.

3. Project Champion: the presence of a champion is a critical faction for successfully manage change 
because he strong influence on the change process within the organization.

4. Clear and systematic planning: presence of clear plan for change.

5. Broad Participation of staff in whole life cycle of ERP implementation.

6. Effective Communication: at all levels of an organization before and during the ERP implementation

7. Feedback: feedback is important to find and identify the source of user resistance.

8. Effective Training/Knowledge Transfer: Training crucial critical success factor in ERP implementation. Everyone who uses ERP systems needs to be trained on how they work and how they relate to the business process

9. Incentives: they help develop strong feelings toward accepting and adopting new systems.

In particular, the following components of change management strategies were common to most projects (Trieu 2010): (Effective communication, Top management support,
Effective training, Project champions, Systematic plan for change)

In addition, ten change management mechanisms were identified as important strategies in (Calvert 2006). This model introduced 2 important variables:

1. Individual's effective use of the ERP system: individual employee's capacity to use the ERP system effectively, as an ultimate dependent variable.

2. Individual's motivation to learn and use the ERP system effectively.

It argues that an employee's capacity to use an ERP system effectively is driven in large part by an employee's Motivation to learn and use the system.

In other words, it is argued that organizations engage in change-management practices to stimulate their employees' motivations to embrace change and to attend to learning to use the ERP system effectively. See Figure 3: Change Management Model (Calvert Model) From (Calvert 2006)

Moreover, an additional variable adequate budget for resources was assumed to be the foundation upon which the extent of the change mechanisms is determined.

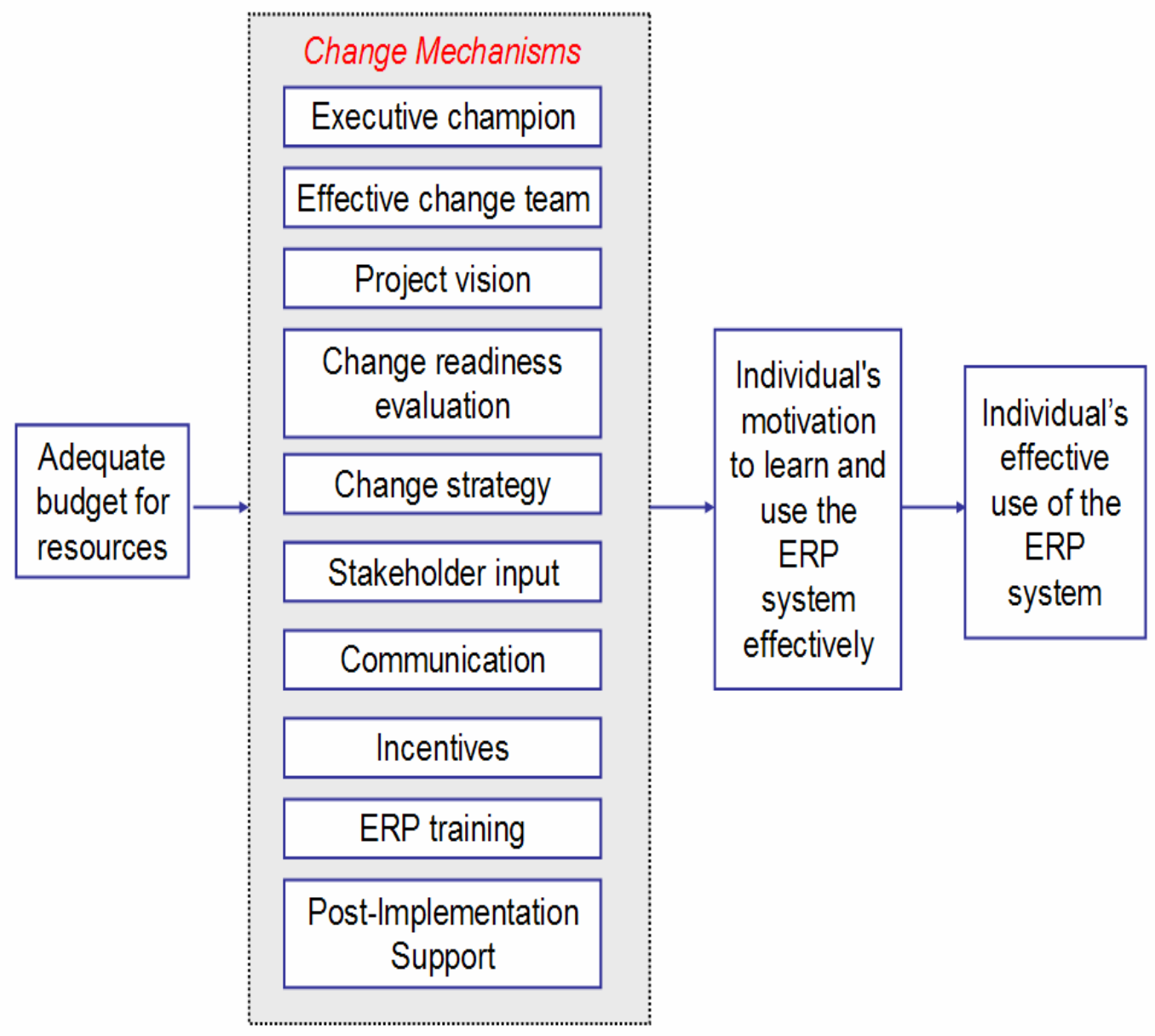

Figure 3: Change Management Model (Calvert Model) 
The ten identified change management mechanisms are(Calvert 2006):

1. Executive Champion: An executive supporter of the ERP initiative is an important motivator for change. The reason is because they are the ones who have the authority to effectively remove cross-departmental political obstacles.

2. Effective Change Team: It is preferred for the team members to be cross-functional, dedicated full-time to the task of managing. Moreover, in selecting the team organization should try to limit its dependent on consultants.

3. Project Vision: A vision specifies what the implementation project is meant to achieve and how it can make a positive impact on the organization employees to work towards achieving the vision.

4. Change-Readiness Evaluation: It is argues that testing for organizational readiness for change is just as important as analyzing technical feasibility. Both the readiness for change and the capabilities for making that change must be present for successful ERP implementation.

5. Change Strategy: A change strategy is a formal plan that details the organizational elements that will be affected by the change and the tactics for introducing that change.

6. Stakeholder input: it is found that people responded favorably to the implementation of new technology when others listened to their suggestions and requirements.

7. Communication: the importance of communication to educate about the project vision, to inform about the implementation project and to help overcome resistance to change.

8. Incentives: providing incentives and/or disincentives to help employees overcome resistance to change. Not only should incentives be offered to help staff overcome resistance to change, incentives also help to retain key implementation staff. An incentive can be a higher pay to those assigned to higher-level, skilled jobs or offering revised titles. Or, an overtime pay to cover the extra work during the changeover phase. Other types of incentives included cash awards, letters of merit, and certificates of recognition.

9. Training: Training should be readily and broadly available to encourage ERP acceptance and use. It is important to consider both practical and conceptual skills when delivering ERP training. Training can also be used as a tool to help overcome some employee's resistance to change.

10. Post-Implementation Change-Management Activities: post-implementation activities, such as mentoring by super-users, training, help-desk support, end-user documentation, newsletters about ERP advanced features and functions, online help, etc., are instrumental. Furthermore, ongoing post implementation change management activities are necessary to help maintain a competent end-user base.
It is important to recognize that most ERP research was conducted in the USA since many companies there already adopted ERP systems (Davenport 1998; Mabert 2000).There has been limited relevant research on some developing countries such as Saudi Arabia. A number of studies have pointed out that popular ERP packages developed by Western countries may not fit the requirement of other organizations in other countries (Mabert 2000; Davison 2002; Ngai 2008). In the following section a case study of a Saudi company will be presented.

\section{CHANGE MANAGEMENT IN NATIONAL PRAWN COMPANY (NPC)}

For the purpose of this study a Saudi company (National Prawn Company) that implement ERP recently was investigated to identify change management factors that contributed to its success and failure.

\subsection{Company Background}

Covering an area of approximately 250sq $\mathrm{km}$ on the Red Sea Coast in Saudi Arabia the privately owned, NPC is among the largest, fully integrated prawn farms in the world. It is located $150 \mathrm{kms}$ south of the Kingdom's commercial centre, Jeddah, and close to port town of Al Lith. NPC has more than 2,800 employees and help to produce over 15,000 tonnes a year of white prawn for sale in the Kingdom and around the world (NPC)

On 2007 the company started using an ERP system known as Baa $N$ version $4 \mathrm{c}(\mathrm{IV})$. The implementation was not successful and by 2009 , they realized that the results were far below expectation, and therefore decided to upgrade to the latest version of the ERP, version 6. By then, the name of the ERP became Infor $\boldsymbol{L} \boldsymbol{N}$ version 6.1. This was a fresh implementation that commenced in January 2009. They went live on Infor $\mathbf{L N}$ in January 2010. It has been successful.

In both 2007 and 2009 implementation, top management was fully committed to the project. The company vision was to implement a strong, proven ERP that would integrate information from the various parts of the company for consistent management reports which will in turn provide effective decision support. Employees were informed about the company decision and ERP was the only way to go.

\subsection{7 implementation}

Based on interviews with 2009 project managers, the following key factors were identified and may contribute to its failure in 2007 :

- Employees were not prepared enough and there was no buy-in on the part of middle-management and this result in lack of interest and dedication to the system. As a result, they could not expend the required effort and resources to achieve success.

- Different departments did not have a clear idea what their role will be to achieve corporate goals in the exercise, and they did visualize the benefit of the system to them

- Excessive customization as the implementers deemed it necessary to customize the main functions of the system to suit the requirements. This was done through the use of source code which was on their possession. This resulted in a stagnated system that could not be updated as the updates would render the customizations ineffective. 
The implementation was not successful and the software ended up being used only in the finance department. Other departments depended on in-house developed applications and such tools as Microsoft Excel for their report requirements.

\subsection{0 implementation}

In 2010, the change was led by a different manager with the assistant of consultants. The old software had many problems; NPC decided to use the latest version of Baan, now known as Infor LN 6.1. The implementation was successful. The following practices were established and may have contributed to its success:

\section{a. More evaluation and analysis were done before implementation}

Analysis documents from the previous implementation were studied. More user interviews were conducted. Potential vendors were invited to conduct business studies before presenting their proposals. The NPC project manager had prior experience in similar projects

\section{b. Less user resistance}

Management's commitment to provide necessary manpower resources to run the system coupled with a clear view of the benefits of the ERP, at departmental level, proved effective in getting sufficient buy-in from middle-management

\section{c. They started with one department at a time. They studied their requirement and planned change accordingly}

Detailed process study and requirement analysis was conducted at departmental level, involving key staff of the departments with sound process knowledge and analytical skills. Care was taken not to pay too much attention to unpractical desires which tend to present obstacles more than anything else.

\section{d. Stake holder's feedback was considered}

Key figures in top management were involved throughout the implementation exercise. At key mile-stones, project status would be presented to them and they would give valuable feedback

\section{e. Effective communication practices}

- Top management would get status update from their middle management.

- Regular status update presentations were held to discuss all issues in the exercise.

- Feedback from management was provided directly to the implementation team and even via their key staff who were members of the implementation team

\section{f. The training was done by training key users, and then they become responsible for their departments}

Key staffs, preferably involved in the previous implementation, were trained to provide training to end users and eventually monitor usage

\section{g. Training}

The existing training center at the company was enhanced to cater for the training needs during and after the implementation

\section{h. Incentives}

Key users were promised special bonuses depending on success rate and individual efforts and dedication demonstrated.

\section{i. During and after implementation exercise, support escalation was as follows}

- $\quad$ End user reports problem to key user

- Key user attempts to resolve the problem. If he cannot, he forwards it to ERP support section in IT department;

- ERP support section attempts to resolve the problem. If unsuccessful, the problem is forwarded to ERP experts that are leading the implementation.

- If unresolved, the problem is submitted to Infor via Infor support website. The fix is downloaded from the site, installed, and tested on a test environment before being installed on the production environment

\section{j. Additional post-implementation support}

An annual maintenance contract with the implementation partner company binds them to provide support services as well as help in the optimization phase.

Nevertheless, it is worthwhile to state that effort required for a full implementation was grossly under-estimated, resulting in the need to obtain management approval for more financing. The support was granted and the implementation was successful.

\section{CONCLUSION}

Change management is important because it helps understand change and its effects on the organization and on people in the organization which leads to successful ERP implementation. In this paper, different methodologies for change management were reviewed and presented.

While different researchers proposed different methodologies for change management, they all included activities that help organizations transition from a current state to desired future state during the implementation of ERP systems to achieve the organizational outcome. It is central to recognize that differences don't only exists among those reviewed methodologies; change management tasks are not the same even in one ERP project as different groups and individuals will be affected differently and therefore will need different strategies. In addition, more research on ERP implementation, change management and country related issues need to considered.

\section{REFERENCES}

[1]. Aladwani, A. (2001). "Change management strategies for successful ERP implementation." Business Process Management Journal, Emerald Group Publishing Limited 7 (3): 266-275(210)

[2]. Almudimigh, A., Zairi, M. (2001). "ERP systems implementation: A best practice perpective and a proposed model." The European Centre for Total Quality Management (ECTQM), Report No. R-01-01.

[3]. Appleton, E. L. (1997). "How to Survive ERP", Datamation 43(4): 50-53. 
[4]. Calvert, C. (2006). "A Change-Management Model for theI mplementation and Upgrade of ERP Systems." AISel, ACIS 2006 Proceedings

[5]. Chen, C., Law, C., Yang S. (2009). "Managing ERP Implementation Failure: A Project Management Perspective", IEEE, TRANSACTIONS ON ENGINEERING MANAGEMENT 56(1): 157-170.

[6]. Davenport, T. (1998). "Putting the enterprise into the enterprise systems", Harvard Business Review: 121-131.

[7]. Davison, R. (2002). "Cultural complications of ERP," 45(7): 109-111.

[8]. Foster, S., Hawking, P., Zhuh, C. (2007). The Human Side of ERP implementation: Can Change Management Really Make a Difference? Research and Practical Issues of Enterprise Information Systems II,. Boston, Springer. 1: 239-249.

[9]. Hawking, P., Foster, S., Stein, A (2004). ERP II \& Change Management: The Real Struggle for ERP Systems Practices. Managing Business with SAP: Planning, Implementation and Evaluation, Hershey PA, IDEA Group

[10]. Jing, R., Qiu, X. (2007). "A Study on Critical Success Factors in ERP Systems Implementation." Service Systems and Service Management, 2007 International Conference 1-6.

[11]. Joshi, K. (1991). "A Model of Users' Perspective on Change: The Case of Information Systems Technology Implementation." MIS Quarterly 15(2): 229.

[12]. Kemp, M. J., Low G.C. (2008). "ERP innovation implementation model incorporating change management", Business Process Management Journal 14(2): 228-242.

[13]. Kerimoglu, O., BaUoglu, N. (2006). "Optimizing the Change Management of Enterprise Resource Planning Systems Implementations", IEEE, PICMET 2006 Proceedings, 9-13 July: 8-13
[14]. Kotter, J. P., Schlesinger (1979). "Choosing Strategies for Change, " Harvard Business Review 57(2): 106-114.

[15]. Mabert, V., Soni, A., Venkataramanan, M. (2000). "Enterprise resource planning survey of U.S. manufacturing firms", Production and inventory Management Journal 41: 52-58.

[16]. Nah, F., Lau, J., Kuang J. (2001). "Critical factors for successful implementation of enterprise systems." Business Process Management Journal 7(3): 285.

[17]. Nah, F., Zuckweiler, K., Lau, J. (2003). "ERP Implementation: Chief Information Officers' Perceptions of Critical Success Factors." INTERNATIONAL JOURNAL OF HUMAN-COMPUTER INTERACTION 16(1): 5-22.

[18]. Ngai, E. W. T., Law, C.C.H., Wat,F.K.T. (2008). "Examining the critical success factors in the adoption of enterprise resource planning", Compute Industry (Ind) 59: $548-564$.

[19]. NPC. "National Prawn Company website", Retrieved January 3, 2011, from http://www.robian.com.sa/home.html

[23]. Ross, J. W. (1999). "Surprising Facts About Implementing ERP", IEEE IT professional 1(4): 65-68.

[24]. Shang, S., Su, T. (2004). "Managing User Resistance in Enterprise Systems Implementation", AIS AMCIS 2004 Proceedings: $148-153$.

[25]. Trieu, H., Kuzic, J. (2010). "Change Management Strategies for the Successful Implementation of Enterprise Resource Planning Systems", IEEE, 2010 Second International Conference on Knowledge and Systems Engineering: 178-182.

[26]. Zafar, A., Zbib I., Arokiasamy S., Ramayah T., Chiun L., (2006). "Resistance to change and ERP implemetation success: The moderating role of change management initiatives." Asian Academy of Management Journal 11(2): 1-17. 